\title{
Endoscopic placement of feeding tubes
}

\author{
GABOR P KANDEL, MD, FRCPC
}

\begin{abstract}
It is no exaggeration to say that percutaneous gastrostomy has revolutionized the feeding of disabled patients with intact gastrointestinal tracts. The most common indication is inability to swallow. It is generally best to place a gastrostomy tube early to prevent malnutrition and minimize complications of procedures on poorly nourished tissue. If a patient is expected to live for only weeks to months, nasoenteric feedings are the nutritional route of choice. Contraindications to percutaneous gastrostomy include coagulation disorders, upper gastrointestinal fistulas, intestinal obstruction, varices, peritoneal dialysis, septicemia and esophageal obstruction. Three techniques are described: 'pull,' 'push' and 'introducer.' The most frequently reported complications are wound infection and pneumoperitoneum. Now that multiple methods for successful insertion of endoscopic percutaneous feeding tubes have been described, the literature appears to be concentrating on complications of the various techniques. Nevertheless, compared to the other options available for patients unable to swallow (allowing malnutrition to proceed, tube feeding, surgical gastrostomy, parenteral nutrition), percutaneous gastrostomy is the procedure of choice in virtually all cases if the intestine is functioning. Can J Gastroenterol 1990;4(9): $616-620$
\end{abstract}

Key Words: Nutrition, Percutaneous endoscopic gastrostomy, Review

\section{Mise en place des sondes d'alimentation sous endoscopie}

RESUME: La gastrostomie percutanée a révolutionné l'alimentation des patients débilités dont les voies gastrointestinales sont intactes. La dysphagie est l'indication la plus commune de la gastrostomie. Il est généralement préférable de placer une sonde d'alimentation rapidement pour prévenir la malnutrition et réduire les complications attribuables à l'alimentation médiocre des tissus. S'il n'est pas probable que le patient vive au-delà de quelques semaines ou quelques mois, l'alimentation par voie naso-entérique est l'approche nutritionnelle de choix. Les contre-indications de la gastrostomie percutanée comprennent les troubles de coagulation, les fistules des voies gastro-intestinales supérieures, l'occlusion intestinale, les varices, la dialyse péritonéale, la septicémie et l'occlusion de l'oesophage. Trois techniques consistant à "tirer", "pousser" et "introduire" sont décrites. Les complications les plus fréquemment rapportées sont l'infection de la lésion et le pneumopéritoine. Après s'être longtemps attachés à décrire les multiples méthodes permettant l'insertion réussie des sondes d'alimentation percutanée par voie endoscopique, les auteurs semblent désormais s'intéresser aux complications propres aux diverses techniques. Néanmoins, quand on les compare aux autres options accessibles aux patients incapables d'avaler (malnutrition autorisée, alimentation par sonde, gastrostomie chirurgicale et nutrition parentérale), la gastrostomie percutanée est la procédure de choix dans presque tous les cas.

Department of Medicine, The Wellesley Hospital, Toronto, Ontario

Correspondence and reprints: Dr GP Kandel, Department of Medicine, The Wellesley

Hospital, Toronto, Ontario M4Y IJ3
S GNIFICANT STRIDES HAVE BEE made in the past 20 years in the are? of nutritional support. Perhaps the most important has been a growing apprecia. tion of the importance of ensuring prop. er nutrition for all patients, particulariy when their illness precludes alimenta. tion for more than seven to 10 days (1). It has become clear that prevention of malnutrition by maintaining optimal nutrition is preferable to treating al. ready developed malnutrition (2).

Parenteral nutrition is often used in hospitalized patients for delivering nutritional support, but enteral feeding is the route of choice when the gastro. intestinal tract is functioning. Com. pared to parenteral nutrition, enteral feedings are not only safer, but in most instances also more efficacious and less expensive (2). Feedings can be pro. vided through 7 French weighted-tip nasoenteric tubes. If the tube can bt. passed beyond the pylorus, there is no: risk of aspiration and in some patients the small diameter of the tube ensures patient comfort and compliance. However, most patients find nasoenteric tubes uncomfortable, particularly if they must remain in place for a pro. longed period. Moreover, because of their small size, such tubes are proneto frequent occlusion and dislodgement.

Surgical gastrostomy has been carried out for over a century. The two greatest advantages of this technique are first, that the feeding tubes have a large diameter ( 24 to 30 French), ensut ing that occlusion is rare, and second, that they are positioned on the upper abdomen, thereby not interfering with patient comfort. The only disadvantage of surgical gastrostomy is that general 
anesthesia and laparotomy are required, with all of the attending risks.

Thus for many years no satisfactory method was available to provide nutrition for ill patients. In 1981 Gauderer and Ponsky (3) described a technique for percutaneous insertion of a gastrostomy feeding tube under endoscopic control. Numerous reports since then have confirmed that percutaneous gastrostomy tubes can indeed be safely inserted without subjecting patients to the risk of surgical laparotomy (4-9).

\section{INDICATIONS}

In virtually all series, the most common indication for feeding gastrostomy tubes is inability to swallow secondary to central nervous system injury such as dementia, stroke, motor neuron disease, myasthenia gravis or brain tumour ( 5 10). Neoplasms in the oropharynx, injuries to the face and neck, and other otolaryngological diseases are also indications. Inability to swallow from severe psychomotor disease, birth injury, asphyxia and congenital disease constitute common indications in children.

It is often difficult to decide the proper route of nutrition when the prognosis is unknown. For example, should a percutaneous gastrostomy tube be inserted in a patient who has recently had a stroke preventing normal glutition?

In such cases, a small bore ( 7 French) nasogastric feeding tube should be inserted; however, if the patient finds this uncomfortable (as most do), the dilemma of whether or not to insert a percutaneous feeding tube persists. While no firm guidelines can be offered, it is generally best to place a gastrostomy tube early. This prevents malnutrition and minimizes complications, since the invasive procedure is done on well nourished tissue. Should the patient improve, it is usually technically trivial to remove the feeding tube.

Another particularly common problem in clinical practice is whether or not to offer gastrostomy feedings to patients with dementia or other irreversible conditions. This is an ethical decision, but it is important to emphasize that both insertion of gastros- tomy tubes and their postoperative care are usually relatively simple and do not constitute "invasive aggressive life saving measures."

On the other hand, if a patient is expected to live for only weeks to months, nasoenteric feedings are the nutritional route of choice.

Gastrostomy feeding tubes have also been described as useful in children requiring unpalatable medications, in maintaining elemental feedings in inflammatory bowel disease, and for providing longstanding gastric decompression in obstructive bowel diseases (11).

\section{CONTRAINDICATIONS}

Percutaneous gastrostomy should not be offered to patients with coagulation disorders unless they can be at least temporarily corrected, and not in the presence of ascites or peritoneal diseases. Upper gastrointestinal fistulas, intestinal obstruction and gastric and esophageal varices are also considered contraindications by most authorities. Peritoneal dialysis is a relative contraindication, but gastrostomy feeding tubes can be inserted if the patient is at least temporarily switched to hemodialysis. Septicemia should be treated and esophageal obstruction alleviated as much as possible (esophagus dilated to 36 French) before a percutaneous tube is inserted. Gastrostomy can be performed safely, but exceptional care and skill is required in the presence of previous abdominal surgery (especially partial gastrectomy) or ventriculoperitoneal shunts (12).

\section{TECHNIQUES}

Three techniques have been described: the 'pull' (Ponsky-Gauderer) $(3,4)$; the 'push' (Sacks-Vine) $(6,7)$; and the 'introducer' (Russell, Brotman, Norris) (13).

The first steps are the same in all three methods. Feedings are withheld for at least $12 \mathrm{~h}$ before the procedure, and consideration given to prophylactic antibiotics. Gargling with povidoneiodine has been recommended to minimize colonization of the feeding tube as it passes through the mouth en route to the stomach (6). The esoph- agus is then intubated with an endoscope in the usual manner after intravenous sedation and topical anesthesia of the posterior pharynx. Ideally, two assistants are present, one to ensure constant oropharyngeal suction, and the other to puncture the anterior abdominal wall. Most brands of gastroscope are suitable for percutaneous gastrostomy, although if the pull or push techniques are used, it is important that the biopsy channel of the endoscope be large enough to allow passage of a snare. If a videoscope is to be used, there should be sufficient light emitting from the tip of the gastroscope to allow proper abdominal wall transillumination.

While the upper gastrointestinal tract is inspected endoscopically, the assistant prepares the feeding gastrostomy tube. Then a site is selected at which to puncture the anterior abdominal wall. This is a crucial step. The optimal site is the point at which the stomach and anterior abdominal wall are in closest contact without interposed tissue. This site is recognized by inspection of the anterior abdominal wall after the room lights are dimmed, and searching for transillumination on the anterior abdominal wall from the anteriorly deflected gastroscope. Finger pressure at the site of greatest illumination should cause marked indentation of the stomach wall, visualized endoscopically. Most often the optimal site will be the left upper quadrant, about two-thirds of the distance from the umbilicus to the left costal margin. Occasionally the stomach is too small or too high, and the anterior abdominal wall and stomach simply cannot be closely interposed. This can easily be recognized by failure to observe a point of bright illumination and/or inability to detect a definite indentation of the gastric wall after gentle finger pressure at multiple sites along the abdomen. In this situation the procedure should be stopped, since the risk of gastrostomy is increased.

Once a site has been selected that is considered satisfactory by the endoscopist, the area is prepared under sterile conditions, and the skin and subcutaneous tissue infiltrated with local 
anesthesia. Using a \#11 scalpel blade, the assistant then makes an incision approximately $1 \mathrm{~cm}$ in length at the chosen site. It is important to ensure that this incision is sufficiently long and deep to allow easy passage of the gastrostomy tube through the subcutaneous tissue; if the incision is too short, the gastrostomy tube will be too tightly apposed against the skin and subcutaneous tissue of the anterior abdominal wall, and tissue necrosis may result from the ensuing ischemia.

The next step in all three techniques is to thrust a cannula through the incision site, through the abdominal wall and then into the stomach lumen under endoscopic visualization while the endoscopist inflates the stomach with as much air as possible. However, the cannula that is used depends upon the chosen procedure (Medicat for pull technique, Seldinger for push and introducer techniques). With the pull technique a suture or silk is passed through the cannula into the gastric lumen, where it is caught by an endoscopic snare. The snare, suture and endoscope are then pulled up through the esophagits and out of the patient's mouth. The 'mouth-end' of the suture is tied to the end of the gastrostomy tube, and the assistant then pulls the 'proximal' end of the suture dangling out of the anterior abdominal wall, while the endoscopist guides the feeding tube itself through the esophagus and stomach, finally visualizing the tube as it emerges from the abdominal wall.

In the push technique a flexible wire rather than a suture is passed through the cannula; this wire is then similarly caught by a snare, and brought out through the mouth. A tapering gastrostomy tube is subsequently 'loaded' onto the wire at the mouth end, and the tube 'pushed' through the open mouth, esophagus and stomach while the wire is held taut. Details of these procedures can be found in the instruction manuals which accompany commercially available percutaneous endoscopic gastrostomy feeding tube kits, as well as in several reviews $(6,10,11,14)$.

A key step with both push and pull techniques comes after the feeding tube has been inserted through the anterior abdominal wall. At this point it is important to decide how tightly to pull the gastrostomy tube against the stomach wall. If the tube is too loose, a proper seal cannot form between the gastric wall and the parietal peritoneum, risking leakage of gastric contents into the peritoneum. On the other hand, if too much pressure is applied and the gastrostomy tube is too tight against the gastric mucosa, mucosal necrosis will occur. Ideally, the 'bumper' (or crossbar) end of the gastrostomy tube should be just touching the gastric wall, without any blanching or dimpling of the mucosa, This can be properly ascertained only by endoscopic visualization - ie, the endoscope must be reinserted in the stomach after the gastrostomy tube is in place. A useful rule of thumb is to tighten the feeding tube as much as possible, while at the same time ensuring that the mucosa is not altered when the tube is rotated. In the past, the tendency was to apply excessive pressure, which led to mucosal necrosis.

The 'introducer' technique also starts with insertion of a cannula through the anterior abdominal wall into the lumen of the stomach. Subsequently, a guidewire is passed through the cannula and the needle removed. Tapered silastic catheters of increasing diameter are then sequentially passed over the guidewire into the gastric lumen, thereby gradually enlarging the diameter of the 'gastrocutaneous fistula.' Then, an introducer surrounded by a peel-away sheath is passed over the guidewire into the gastric lumen, the introducer and wire removed, and a 14 French Foley catheter (or similar tube) inserted through the sheath lumen into the stomach. The sheath is then peeled away and the Foley balloon inflated in the usual manner.

\section{POSTOPERATIVE CARE}

The catheter can be sutured to the skin, but it is just as effective to anchor the tube by a feeding adapter cuff fitted to the cut end of the tube.

Most authorities advise that feedings be withheld for $24 \mathrm{~h}$ to ensure that complications have not occurred $(5,11)$. If the patient is then feeling well and bowel sounds are present without significant abdominal distension, feedings can be started. If enteral feedings have not been given previously, a small amount (100 to $200 \mathrm{~mL}$ ) of a full strength commercial liquid diet (1 $\mathrm{kcal} / \mathrm{mL}$ ) is administered every $4 \mathrm{~h}$, provided no residue remains in the stomach. The volume of feedings given daily is then gradually increased; it is probably best to give feedings only when the patient is upright during waking hours. If the patient was being fed enterally before the tube was in serted, the previous feeding rate can be ordered.

\section{COMPARISON OF TECHNIQUES}

Each of the three techniques outlined above has been reported to be effective and safe, but systematic com. parisons have been rare. Theoretically the introducer technique is the most appealing because there is no oral contamination of the feeding tube and, in patients with pharyngeal or esophageal obstruction, the 'bumper' (or mush. room or crossbar) of the feeding tube does not have to be passed througha possibly obstructed esophagus.

Moreover, only one passage of the gastroscope is required (since the gastrostomy tube is simply a Foley catheter whose position need not be checked endoscopically). On the other hand, there has been less experience with this technique than the others, and difficulties have been described in piercing the gastric wall with the peel. away sheath and introducer; there is a tendency for the introducer to simply push the stomach wall away from the peritoneum. In addition, at least two cases of inadvertent migration of the gastrostomy tube into the peritoneal space have been reported after place ment of the Foley catheter in the stomach $(13,15)$.

The pull and push techniques are so similar that it is difficult to imagine that randomized trials will ever find a sig. nificant difference between them. Probably operator technique is more important than the actual method used to insert the gastrostomy tube. Accord. ingly, it is not surprising that the three 
small series that have compared techniques have shown that, in expert hands, only minimal differences exist between the push and pull methods (16-19).

Most authorities recommend that the novice initially choose one technique to master. Once experience has been gained, the technique should be chosen on the basis of the individual needs of the patient.

\section{PERCUTANEOUS ENDOSCOPIC JEJUNOSTOMY}

A jejunostomy feeding tube rather than a gastrostomy tube should be considered in patients with severe gastric esophageal reflux, pneumonia, delayed gastric emptying or gastric outlet obstruction (20). To insert a jejunostomy feeding tube, the procedure begins exactly as outlined above. However, the feeding tube itself is longer than a gastrostomy feeding tube, and once in the stomach, needs to be guided with a snare into the jejunum. Accordingly such tubes are better termed gastrojejunostomy tubes. Double-lumen tubes (one port in the stomach, the other in the jejunum) can also be used.

\section{ENDOSCOPIST VERSUS RADIOLOGIST}

Multiple publications have demonstrated that percutaneous gastrostomy feeding tubes can be safely inserted by endoscopic control (5-11); similarly, multiple articles in the radiology literature have documented that such tubes can be just as safely inserted percutaneously under fluoroscopic guidance (21-23). A significant advantage of fluoroscopic control is that less expense is incurred because endoscopy is not performed. On the other hand, at least two recent series have shown that endoscopy reveals clinically unsuspected disease in the upper gastrointestinal tract in about onethird of patients $(24,25)$. For example, Wolfsen et al (25) found that of 201 patients undergoing percutaneous endoscopic gastrostomy, 35 had severe reflux esophagitis, 29 peptic ulcer disease, two fungal esophagitis, and two gastric outlet obstruction. The chief ad- vantages ascribed to fluoroscopic control - lack of oral contamination of the feeding tube and percutaneous insertion of the feeding tube itself so that an obstructed esophageal lumen is not a hindrance - are also true for the endoscopic introducer technique.

\section{IS ANTIBIOTIC PROPHYLAXIS NECESSARY?}

In a prospective, randomized trial from the Mayo Clinic (26), cefazolin $1 \mathrm{~g}$ intravenously $30 \mathrm{mins}$ before gastrostomy insertion decreased the incidence of peristomal infection to $7 \%$ compared to $32 \%$ after placebo. Similar efficacy of preprocedural antibiotics was demonstrated in another small trial (27). Many of the peristomal infections were not clinically significant (27), and in most centres the incidence of peristomal sepsis has fallen since the appreciation of the importance of not pulling the gastrostomy tube too tightly against the stomach wall. Accordingly, in a recent study from Seattle, wound infections were rare, and no benefit was observed from cefazolin prophylaxis (28). The present authors' experience has been similar.

\section{COMPLICATIONS}

The most frequently reported complication is wound infection, usually treatable by antibiotics and local debridement $(5-10)$. Necrotizing fasciitis has also been described, occasionally causing death $(29,30)$. These complications are becoming less common as the anterior abdominal wall scalpel incision is being made sufficiently long, and the gastrostomy tube is not being pulled too tightly against the gastric mucosa.

Probably the most frequent current complication is pneumoperitoneum secondary to leakage of air (and presumably fluid) into the peritoneal cavity during the procedure. This problem is clinically significant only if the amount of peritoneal air increases after the gastrostomy tube has been inserted, indicating a continuing leak. In this situation, water-soluble contrast material should be installed through the gastrostomy tube under radiological guidance. Leakage from the stomach into the peritoneal cavity is most often due to poor approximation of the stomach against the anterior abdominal wall, in which case gentle traction on the gastrostomy tube can sometimes solve the problem. If the leakage is minimal, strict bowel rest (ie, nothing by mouth or feeding tube), nasogastric suction, antibiotics (eg, cefoxitin or a combination of drugs covering both Gram-negative aerobes and anaerobes) and histamine $\mathrm{H}_{2}$ antagonists (to decrease the volume and acidity of gastric secretion) are indicated. However, if signs of sepsis develop, or if perforation of a hollow viscus has occurred, then surgery is usually necessary. If pulmonary aspiration occurs, the gastrostomy should be converted to a jejunostomy. In several reports, a number of gastrocolic fistulas occurred, usually controlled by simple withdrawal of the feeding tube (31). In other cases, however, surgery has been necessary to close the fistula. Other reported complications include inadvertent passage of the gastrostomy tube through the liver, lodging of the gastrostomy tube in the esophagus, and hematomas at the gastrostomy site (11).

If the gastrostomy tube becomes dislodged within $24 \mathrm{~h}$ of being inserted, some degree of peritoneal soilage is expected to occur. Usually conservative management, as outlined above for pneumoperitoneum, is satisfactory, although surgical intervention is necessary if clinical deterioration occurs.

After the procedure it is good practice to observe the area of skin around the gastrostomy site each day. Rarely, erythema and fluctuation can be detected around the tube, indicating formation of a peritubal abscess. This can almost always easily be managed by incising the area with a \#11 scalpel blade.

According to the literature, the 30 day procedural mortality of percutaneous gastrostomy insertion is high, but the majority of these deaths are due to the underlying medical condition of the patient and not to the gastrostomy insertion. Major complications (death, gastric perforation, bleeding) occur in most series in 3 to $5 \%$ of cases. Pulmonary aspiration is the most frequent late complication. 


\section{REFERENCES}

1. Bastow MD, Rawlings J, Allison SP. Benefits of supplementary tube feedings after fractured neck of femur: A randomized controlled study. Lancet 1983;i:143-5.

2. Alpers DH, Clouse RE, Stenson WF. Nutritional planning for patients with protein and calorie deficiency. In: Alpers DA, Clouse RE, Stenson WF, eds. Manual of Nutritional Therapeutics. Boston: Little, Brown and Co, 1983:187-201.

3. Gauderer MWL, Ponsky JL. A simplified technique for constructing a feeding gastrostomy. Surg Gynecol Obstet 1981;152:82-5.

4. Ponsky JL, Gauderer MWL. Percutaneous endoscopic gastrostomy: A non-operative technique for feeding gastrostomy. Gastrointest Endosc 1982;27:9-11.

5. Larson DE, Burton DD, Schroeder KW, DiMagno EP. Percutaneous endoscopic gastrostomy: Indications, success, complications, and mortality in 314 consecutive patients. Gastroenterology 1987;93:48-62.

6. Mamel JJ. Percutaneous endoscopic gastrostomy. Am J Gastroenterol 1989;84:703-10.

7. Foutch PG, Wods CA, Talbert GA, Sanowski RA. A critical analysis of the Sacks-Vine gastrostomy tube: A review of 120 consecutive procedures. Am J Gastroenterol 1988;83:812-5.

8. Steffes C, Weaver DW, Bouwman DL. Percutaneous endoscopic gastrostomy. New technique - old complications. Am Surg 1989;55:273-7.

9. Sangster W, Cuddington GD, Bachulis BL. Percutaneous endoscopic gastrostomy. Am J Surg 1988;155:677-9.

10. Ponsky JL, Gauderer MWL. Percutaneous endoscopic gastrostomy: Indications, limitations, techniques and results. World J Surg 1989;13:165-70.
11. Ponsky JL, ed. Techniques of Percutaneous Gastrostomy. New York: IgakuShoin, 1988:5-7.

12. Stellato TA, Gauderer MWL, Ponsky JL. Percutaneous endoscopic gastrostomy following previous abdominal surgery. Ann Surg 1984;200:46-50.

13. Russell TR, Brotman M, Norris F. Percutaneous endoscopic gastrostomy: A new simplified and cost-effective technique. Am J Surg 1984;148:132-7.

14. Gauderer MW, Stellato TA. Gastrostomies: Evolution, techniques, indications, and complications. Curr Probl Surg 1986;23:658-719.

15. Miller R, Kummer B, Kotler D, et al. Percutaneous endoscopic gastrostomy: Procedure of choice. Ann Surg 1986;204:543-5.

16. Kosarek RA, Ball T, Ryan J. Percutaneous endoscopic gastrostomy: When push comes to shove; a comparison of two insertion methods. Gastrointest Endosc 1985;31:131. (Abst)

17. Hogan RB, Demarco DC, Hamilton JK, et al. Percutaneous endoscopic gastrostomy: To push or pull: A prospective randomized trial. Gastrointest Endosc 1986;32:253-8.

18. Monbraind J, Colturi T. Percutaneous endoscopic gastrostomy: Which technique is best? Gastrointest Endosc 1987;33:185. (Abst)

19. Deitel M, Bendago M, Spratt EH, Burul C], To TB. Percutaneous endoscopic gastrostomy by the "pull" and "introducer" methods. Can J Surg 1988;31:102-4.

20. Ponsky JL, Aszodi A. Percutaneous endoscopic jejunostomy. Am J Gastroenterol 1984;79:113-6.

21. Lambiase RE, Dorfman GS, Cronon JJ, Paolella LP, Caldwell ME. Percutaneous alternatives in nutritional support: A radiologic perspective. JPEN 1988; 12:513-20.
22. Ho CS, Yee ACN, McPherson R. Complications of surgical and percutaneous nonendoscopic gastrostomy: Review of 233 patients. Gastroenterolog 1988;95:1206-10.

23. Halkier BK, Ho CS, Yee ACN. Percutaneous feeding gastrostomy with the Seldinger technique: Review of 252 patients. Radiology 1989;171:359. 62.

24. Scott JS, Edelman DS, Unger SW. Percutaneous endoscopic gastrostomy. A mandate for complete diagnostic upper endoscopy. Am Surg 1989;55:85. 7.

25. Wolfsen HC, Kozarek HA, Ball T], Patterson DJ, Botoman VA, Ryan JA. Value of diagnostic upper endos. copy preceding percutaneous gastros. tomy. Am J Gastroenterol 1990;85:249-51.

26. Jain NK, Larson DE, Schroeder W, et al. Antibiotic prophylaxis for percutaneous endoscopic gastrostomy. Ann Intern Med 1987;107:824-8.

27. Weg A, Miskowitz P. The efficacy of prophylactic antibiotics for endoscopic gastrostomy. Gastrointest Endosc 1987;33:165. (Abst)

28. Kozarek RA, Ball TJ, Patterson DJ. Prophylactic antibiotics in percutaneous endoscopic gastrostomy: Need or nuisance? Gastrointest Endosc 1986;32:147-8,

29. Cave DR, Robinson WR, Brotscki E Necrotizing fasciit is following percutaneous endoscopic gastrostomy. Gastrointest Endosc 1986;31:294-9.

30. Person JL, Brower RA. Necrotizing fasciitis/myositis following percutaneous endoscopic gastrostomy. Gastrointest Endosc 1986;32:309.

31. Larson DE, Fleming CR, Ott B], Schroeder KW. Percutaneous endoscopic gastrostomy: Simplified access for enteral nutrition. Mayo Clin Proc 1983;58:105-7. 


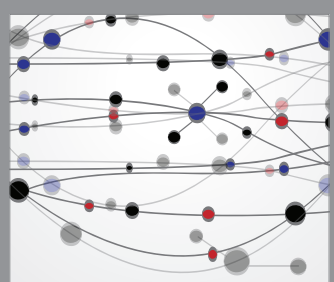

The Scientific World Journal
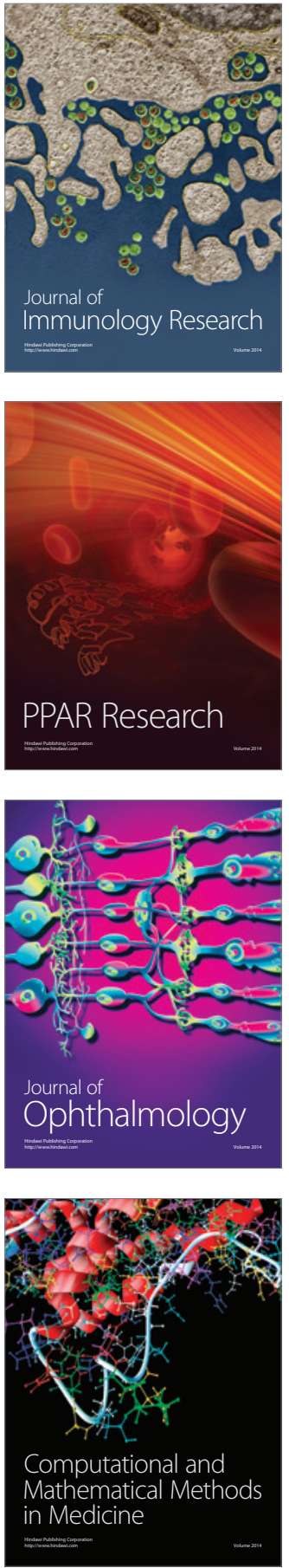

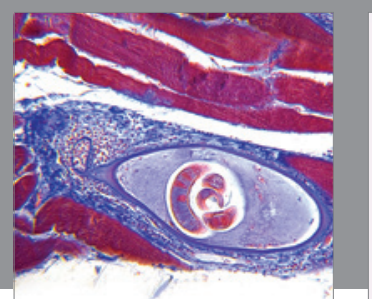

Gastroenterology Research and Practice

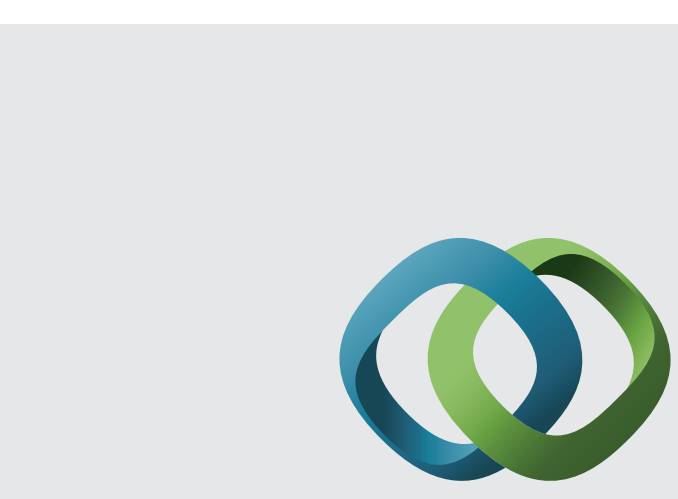

\section{Hindawi}

Submit your manuscripts at

http://www.hindawi.com
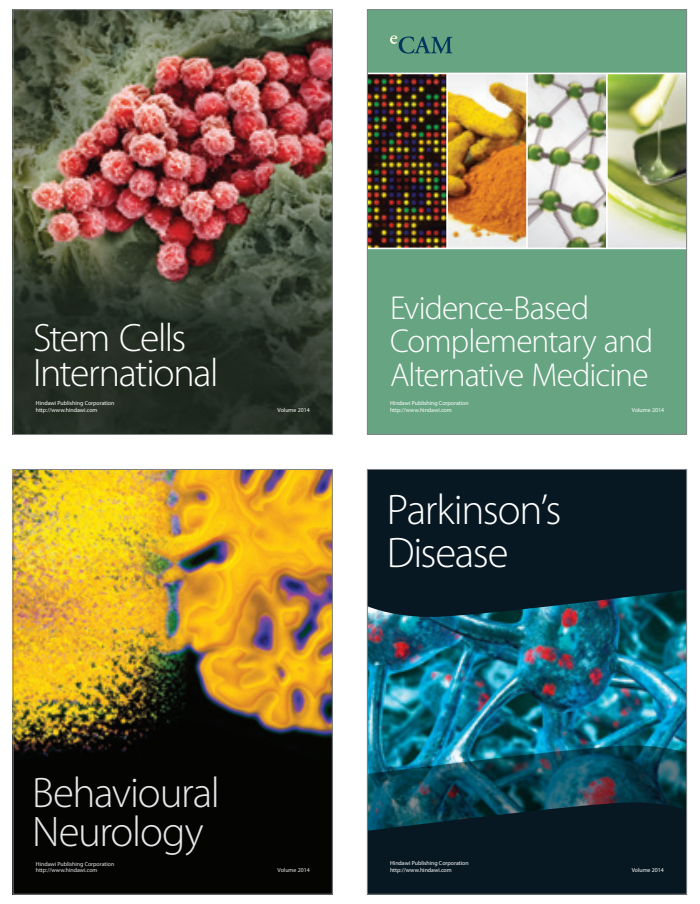
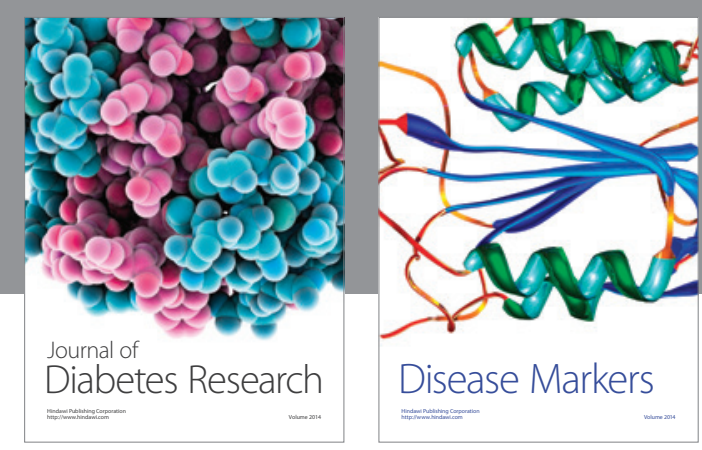

Disease Markers
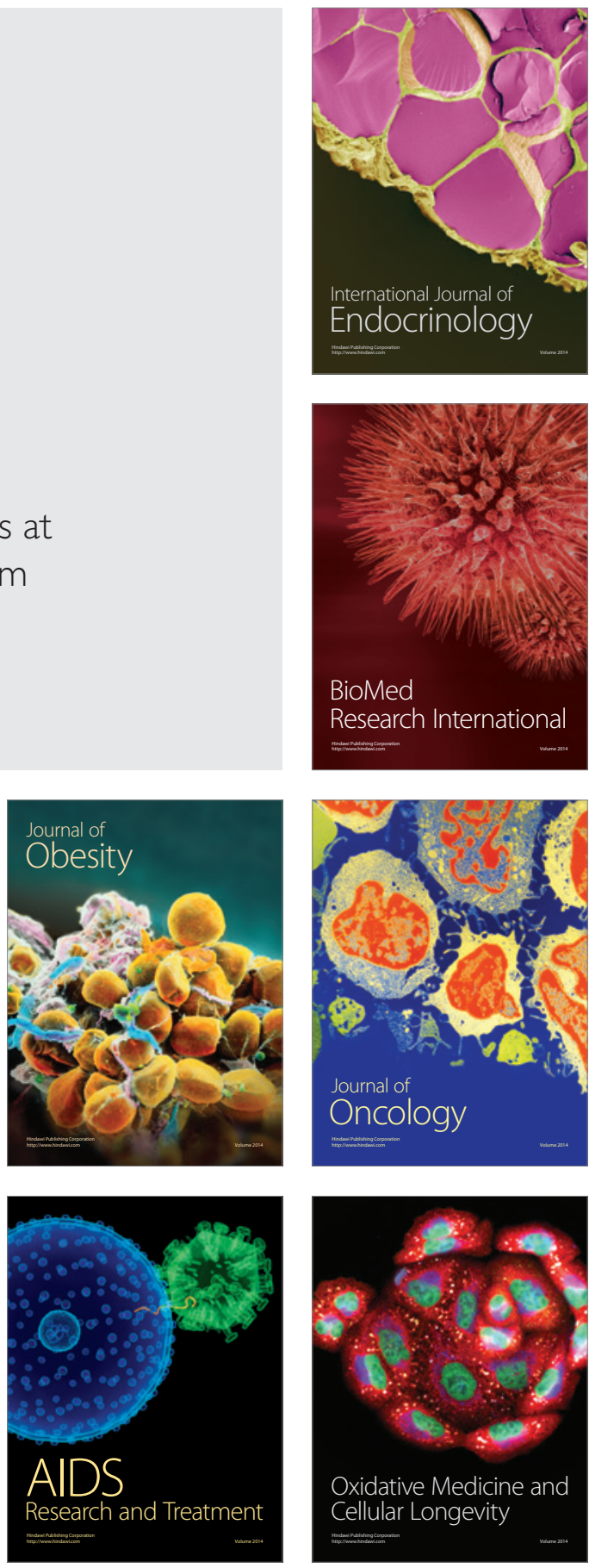